\title{
Research regarding the design and manufacturing of hand orthosis by using Fused Deposition Modeling technology
}

\author{
Ancuţa Păcurar,", Monica Rău², Răzvan Păcurar ${ }^{1}$, Eugen Guţiu ${ }^{1}$, Laura Bacali ${ }^{2}$, and \\ Cosmin Cosma ${ }^{1}$ \\ ${ }^{1}$ Technical University of Cluj-Napoca, Manufacturing Engineering Department, B-dul Muncii 103- \\ 105, 400641, Cluj-Napoca, Romania \\ ${ }^{2}$ Technical University of Cluj-Napoca, Department of Management and Systems Engineering, B-dul \\ Muncii 103-105, 400641, Cluj-Napoca, Romania
}

\begin{abstract}
The article presents the designing of an orthosis used for immobilization of the hand after a surgical operation or bone fracture. Finite element analysis was used for the shape optimization of the orthosis, in close connection with constrains given by the mechanical resistance of the part and constrains given by the technological parameters used in the AM process. The orthosis was finally manufactured by Fused Deposition Modeling at the Technical University of Cluj-Napoca, the results could be implemented in the Romanian medical system.
\end{abstract}

\section{Introduction}

The development of new manufacturing technologies that are able to realize a physical product by adding material represented a reference moment for the research and technological progress. Realization of products using Additive Manufacturing (AM) technologies has the potential of improving not only the designing process, but also the rapid development of a product in medical domain [1], [2]. For the realization of an implant, the process starts with a 3D model that is obtained by $3 \mathrm{D}$ scanning or Computer Tomography (CT), which is afterwards redesigned and prepared accordingly for the AM process, by setting the adequate technological parameters and part orientation within the working platform of the AM equipment [3]. Prosthesis which are produced for hands or legs like orthosis, realized for the sustaining of different fractured members, which are manufactured in a classical way leads to rejection of body organisms in almost all of the cases due to the fact that the skin does not breathe under the gypsum, causing infections or pains due to the low mobility for daily routines. By using AM technologies is foreseen to made orthosis that are able to keep their key characteristics of immobilization, but with an increased level as compared to the classical variants, these types of orthosis being redesigned also from the aesthetic point of view, being able to be realized in different colors. Different types of materials are foreseen to be used in different layers with the aim of offering

\footnotetext{
${ }^{*}$ Corresponding author: ancuta.costea@,tcm.utcluj.ro
} 
stronger supports where it is needed (the material being tough and rigid in that particular areas), but also flexibility in sensitive areas (the material used in these cases being more soft, with characteristics similar to silicone gel) [4]. For the realization of such types of orthosis, it is required the 3D scanning of the segments where these prosthesis will be mounted on, editing of these segments using 3D CAD software's, preparing of the orthosis for printing and AM process of the part right at the end [5]. In this article, the results reached by the authors in the field of designing and manufacturing of orthosis are presented, as they were reached at the Technical University of Cluj-Napoca using AM technologies. These types of orthosis which are presented in the article are destined for closed fractures, but also for the orthosis that can be used in the cases when no surgical operation is needed.

\section{Designing of the medical orthosis to be manufactured by Fused Deposition Modeling Technology}

For the realization of the orthosis, fused deposition modeling (FDM) technology has been considered. To produce customized orthosis, several steps are required to be followed, as they are shown in Fig. 1 and presented below:

1. Making the radiography for the arm to localize the fracture and to establish the diagnostic and treatment; this activity was developed by an orthopedic doctor;

2. Optical scanning of the fractured arm;

3. Designing of the orthosis by CAD programs;

4. Selecting the fixing system of the components;

5. Developing finite element analysis to estimate the von Mises stresses of part;

6. Importing the 3D model in "*.STL" format within Ultimaker Cura 3.6 program;

7. Defining the technological parameters for AM process;

8. Selecting the material from which the orthosis will be made of;

9. Manufacturing of the orthosis by FDM technology;

10. Manual cleaning of the orthosis (supports removal).

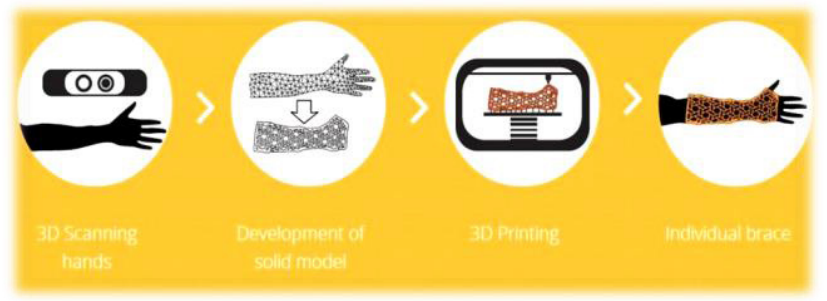

Fig.1. Stages required to be followed for the realization of personalized orthosis by AM [6]

Radiographies are necessary for establishing the fracture gravity, for precise localizing of the fracture and level of joints involvement. In the analysed case, as one may notice in Fig.2, it was localized a closed fracture (indicated with arrow in Fig.2) which do not require surgical operation and for which the orthosis that will be designed is intended to be used in the convalescence period, the orthosis being required to be carried on after the use of the gypsum apparatus.

Initial 3D scanning process of the arm was obtained using the Go!SCAN 3D 50TM scanner which is available at the Faculty of Machine Building at the Technical University of Cluj-Napoca (TUCN). For post-processing of the reached scanning, Vxelements software was used. With the help of this software a very complex surface model of the arm of the patient has been obtained as one may notice in Fig. 3, with $30 \mu \mathrm{m}$ level of the accuracy and high level of triangulation. The scanning has been performed by keeping the arm of the patient in same position and by using different types of objects required for the delimitation of the scanned area (see the second image presented in Fig. 3). 


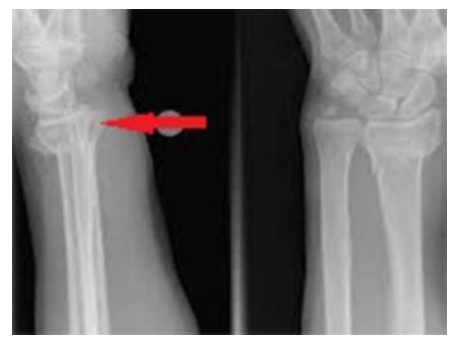

Fig.2. Radiography of the fractured arm
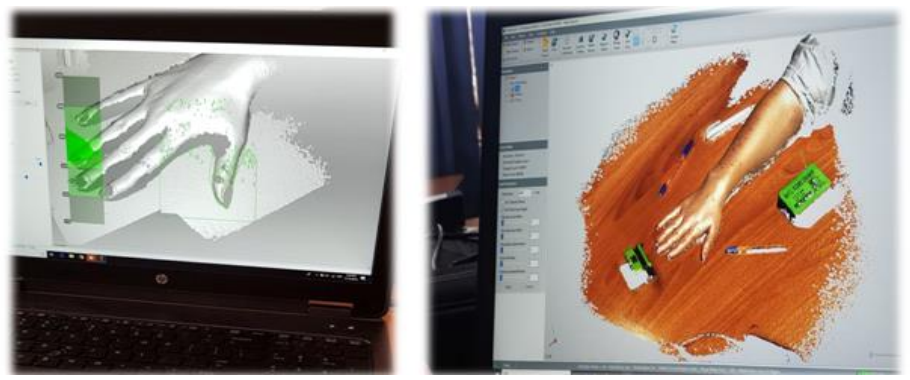

Fig.3. Scanning of the arm and delimitation of scanning area

For smoothing the scanned model, the Meshmixer software has been used, as one may notice in Fig. 4, as for reaching the inversed surface, SolidWorks software program has been used (see Fig.5). In Fig 5 it is possible to see that the CAD design has been customized from the aesthetical point of view as well. Finally the part has been saved as an "*.STL" file, this type of file being required to be used for the AM process.

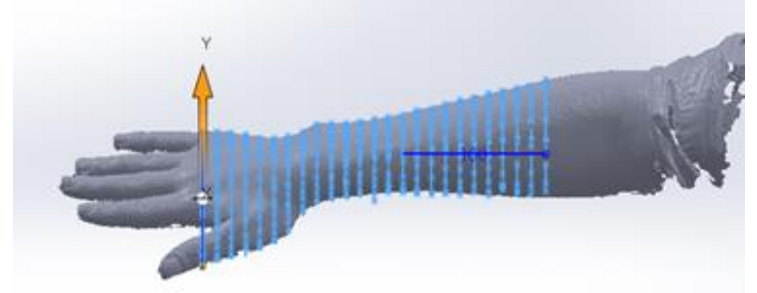

Fig.4. Smoothing of scanned surfaces using Meshmixer program
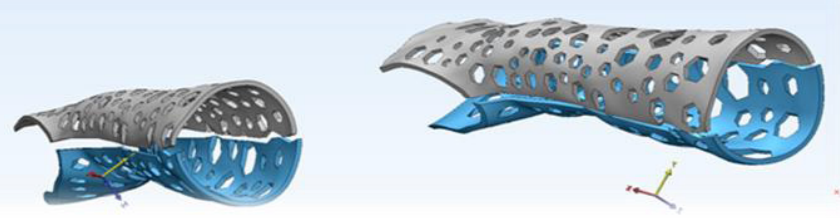

Fig.5. 3D model of the inversed surface reached by using SolidWorks CAD program

The holes which were designed in the part, destined for the ventilation of hand (with a distance between them in the limits of 4-10 mm) were made in such way that the mechanical resistance of the orthosis will not be affected (taking into consideration the existing constraints of the equipment used for printing at the end). 


\section{Finite element analysis of the orthosis}

In order to estimate the mechanical behaviour of the orthosis, finite element analysis has been considered using SolidWorks Simulation program. For the static analysis performed, the material which was considered for the analysis was PLA. The material's characteristics were taken into account as they were taken from the website of the producer of this type of material for AM process (see Fig.6).

\begin{tabular}{|l|l|l|}
\hline Property & Value & Units \\
\hline Shear Modulus & 318.9 & $\mathrm{~N} / \mathrm{mm}^{\wedge} 2$ \\
\hline Mass Density & 1300 & $\mathrm{~kg} / \mathrm{m}^{\wedge} 3$ \\
\hline Tensile Strength & 37 & $\mathrm{~N} / \mathrm{mm}^{\wedge} 2$ \\
\hline Compressive Strength & & $\mathrm{N} / \mathrm{mm}^{\wedge} 2$ \\
\hline Vield Strength & 35.9 & $\mathrm{~N} / \mathrm{mm}^{\wedge} 2$ \\
\hline Thermal Expansion Coefficient & $4.1 \mathrm{e}-005$ & $/ \mathrm{K}$ \\
\hline Thermal Conductivity & 0.13 & $\mathrm{~W} /(\mathrm{m} \cdot \mathrm{K})$ \\
\hline Specific Heat & 1386 & $\mathrm{~J} /(\mathrm{kg} \cdot \mathrm{K})$ \\
\hline
\end{tabular}

Fig. 6. Characteristics of the PLA material considered for the FEA analysis [7]

The kinematical and technological constraints were imposed as showed in Fig. 7. As one may notice, a force of $20 \mathrm{~N}$ was considered as stressing the part.
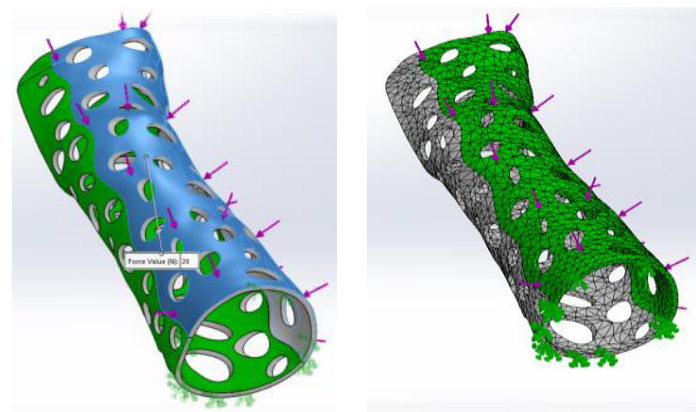

Fig. 7. Constraints imposed and mesh generated for the finite element analysis

The mesh has been generated and von Mises stress has been determined after running the analysis. The maximum value of the stress that has been reached as estimated with the finite element analysis was $10.02 \mathrm{MPa}$, value which is below the admissible limit of PLA material. According to the sheet data of PLA material, the yield limit is up to $35.90 \mathrm{MPa}$ (see Fig.8).

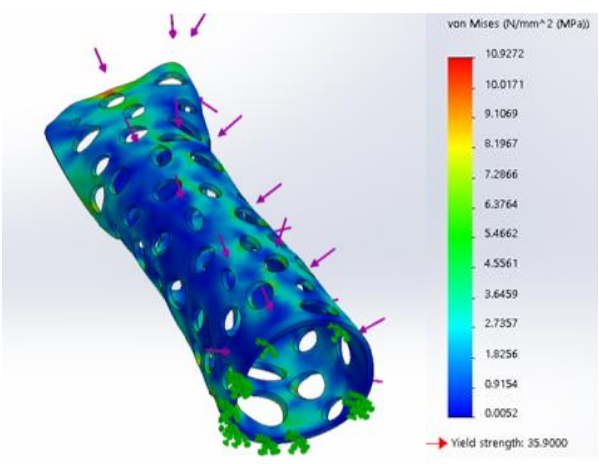

Fig.8. Von Mises stresses distributed in the FDM orthosis 


\section{Manufacturing of the orthosis by FDM}

The 3D model of designed orthosis has been saved as an "*.STL" file and has been imported within the Ultimaker Cura 3.6 program, where the part has been oriented and prepared for the manufacturing process realized using fused deposition modeling (FDM) equipment at the Department of Manufacturing Engineering from the Technical University of Cluj-Napoca (TUCN) (see Fig. 9).
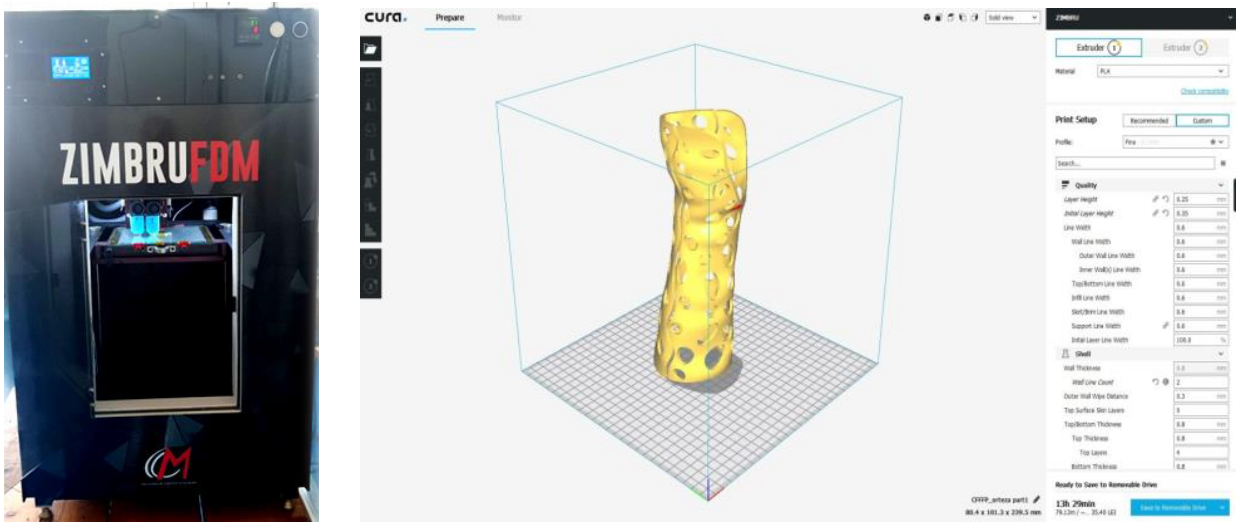

Fig.9. Fused Deposition Modeling equipment from TUCN and part imported within Ultimaker Cura 3.6 program

Technological parameters were set as shown in Fig. 10. As one may notice from Fig. 10 layer thickness has been set at $0.25[\mathrm{~mm}]$ and wipe distance has been set at $0.15[\mathrm{~mm}]$. Infill density was set to a $10[\%]$ value with an infill line distance set to $18[\mathrm{~mm}]$. Temperature of the extruder was set to $205\left[{ }^{\circ} \mathrm{C}\right]$, while printing speed has been set to $50[\mathrm{~mm} / \mathrm{seconds}]$. For the supports the settings were made in such way that when a value of $45\left[^{\circ}\right]$ is reached, the support will have a density of $16[\%]$ in total. Building plate was pre-heated at a temperature of $50\left[{ }^{\circ} \mathrm{C}\right]$, according to the instructions provided by the producer of AM equipment.
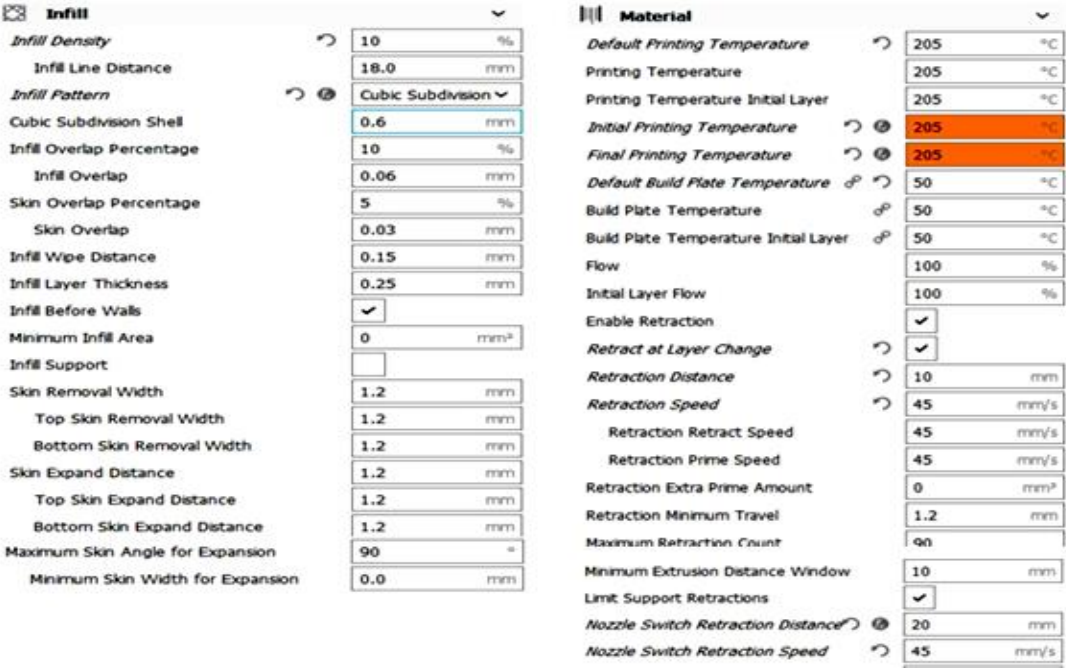

Fig.10. Technological parameters set for the FDM process

The orthosis made by FDM at TUCN is shown in Fig. 11. The weight of the printed orthosis was 97.03 grams, its total length being $293.13 \mathrm{~mm}$. For the printing process, a 
quantity of 143 grams was necessary for the supports. The supports were removed manually, when the printing process was finished on the machine. Total time required for printing of the orthosis was 13 hours and 35 minutes.
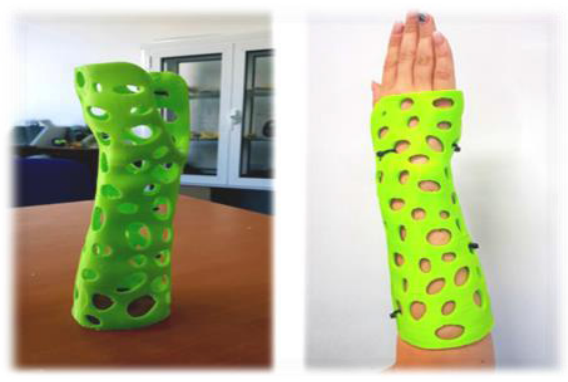

Fig.11. Customized orthosis made by FDM

\section{Conclusions}

AM processes, such as FDM can be successfully used for manufacturing of the customized orthosis. Before designing and printing, radiography is needed in order to localize the fracture and to provide an accurate model of the type of orthosis that is required to be designed and printed. Post-processing of the images in close connection with the $3 \mathrm{D}$ scanning process of the hand are crucial stages in the designing process of the orthosis. There are some limitations in terms of virtual design, the constraints of the AM equipment playing an important role regarding the features that are required to be designed afterwards (e.g. for the ventilation of hand and mechanical resistance of the orthosis while printing, etc.). Finite element analysis that was done before printing was an important step also, due to the fact that it was possible to be noticed that the admissible stress does not the material tensile strength. The orthosis was finally printed successfully using the FDM equipment at the Technical University of Cluj-Napoca in a total time of 13 hours and 35 minutes. Marketing research for the realization of personalized medical orthosis products will be necessary to be done in the future in order to see if FDM technology will be suitable from the economical point of view to replace the traditional methods used for production of new customized orthosis on a much larger scale.

This paper was supported by Romanian Ministry of Research and Innovation (UEFISCDI), Project cod PN-III-P1-1.2-PCCDI-2017-0224 (no.77PCCDI/2018) within PNCDI III. This paper was also supported by the Human Capital Operational Programme agreement POCU/380/6/13/123927 financed from the European Social Fund.

\section{References}

1. D. Manestar, S. Maričić, D. Komljenović, D. Miletić, A. R. Baršić, E. Borović, Laryngoscope, 127, 3 (2017)

2. E. Teutan, V. Maties, D. Mandru, Acta Technica Napocensis, 49, 2, (2006)

3. D. Baila, S. Tonoiu, Applied Mechanics and Materials, 467, (2014)

4. C.S. Borzan Miron, M. Moldovan, V, Bocanet, Revista de Chimie, 69, 4, (2018)

5. I. Molnar; L. Morovic; J. Blaha, IOP Conference-Materials Sci. \& Eng., 448, (2018)

6. Orthosis produced by AM Technologies, https://3dprint.com/43103/3d-printed-cast

7. Characteristics of PLA material, http://2015.igem.org/wiki/CamJIC-Specs-Strength.pdf 